\title{
RESECTION OF THE TOOTH APEX WITH DIODE LASER
}

\author{
Tz. Uzunov ${ }^{1}$, P. Uzunova ${ }^{2}$, T. Uzunov ${ }^{1}$ and R. Grozdanova ${ }^{1}$ \\ ${ }^{1}$ Faculty of Dental Medicine, Medical University - Sofia \\ ${ }^{2}$ Faculty of Medicine, Medical University - Sofia
}

Summary. An "in vitro" experimental study has been carried out on 70 extracted teeth. A laser resection of the root apex has been carried out with diode laser beam with a wavelength of $-810 \pm 10 \mathrm{~nm}$. Sequentially a radiation with increasing power has been applied, as follows: 1,3 W, 2W, 3W, 4W, 5W, 6W, 7W, in electro surgery mode. Successful resection of the tooth apex has been performed at: $3 \mathrm{~W}$; $4 \mathrm{~W} ; 5 \mathrm{~W} ; 6 \mathrm{~W}$ and $7 \mathrm{~W}$ power. It was established that when laser resected the tooth apex carbonizes.

Key words: diode laser, apical osteotomy, "Denlase"

\section{INTRODUCTION}

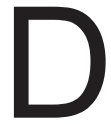

Diode lasers are widely used in the treatment of abscesses, ulcers, teeth whitening, lengthening of tooth crowns, opened and closed curettage, gingivectomy, gingivoplastics, disclosure of implants, incisions, sterilization of root canals, pulp coagulation, gingival sulcus retraction and others [1, 2, 3, 4, 6, 9, 10, 14, 22, 25, 29].

One major problem in the process of the apical osteotomy is the complete resection of the apex of the operated tooth, located in cystic cavity. When the resection is incomplete, granulations remain around the apex and cause relapse. At the apex of the tooth, around the main canal, there are delta shaped microtubules $[5,7,8,11,13,15,16,17,18,19,24,26,27,28,30]$. Numerous microorganisms are found in these microtubules and they cannot be removed by resection with rotation instruments [12, 20, 21, 23, 31, 32]. In the available literature there are no experimental studies on the use of "Denlase" diode laser in apical osteotomy. 


\section{AIM}

The purpose of the study was to establish the minimum power of the laser beam necessary for the apical tooth resection with a diode laser.

\section{MATERIAL AND METHODS}

For this purpose we used a diode laser "Denlase“, which has European certifications CE and TÜV and was kindly provided by „Optica Laser « for experimental work (Fig. 1).

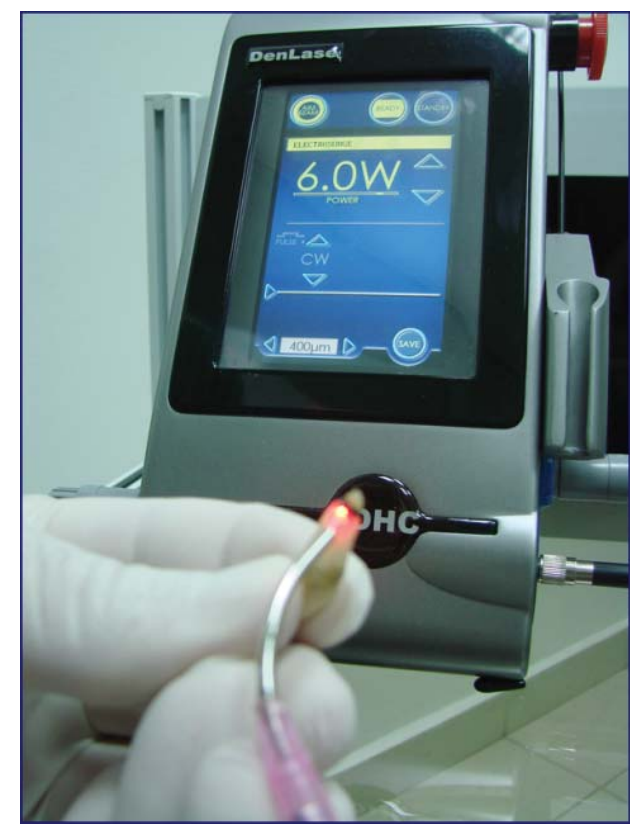

Fig. 1. Laser unit "Denlase"

The study was performed on seventy extracted teeth divided in groups of ten. A laser resection of the root apex has been carried out with laser beam with a wavelength of $-810 \pm 10 \mathrm{~nm}$. Sequentially a radiation with increasing power has been applied, as follows: $1,3 \mathrm{~W}, 2 \mathrm{~W}, 3 \mathrm{~W}, 4 \mathrm{~W}, 5 \mathrm{~W}, 6 \mathrm{~W}, 7 \mathrm{~W}$, in electrosurgery mode. In the study we applied continuous laser radiation - CW, in which the value of the output power is reduced by the amount of light scattered when passing along the optical fiber.

\section{RESULTS}

The obtained experimental results indicate that, at a minimum program specified power $1,3 \mathrm{~W}$, as well as at $2 \mathrm{~W}$ power resection has not been performed (Fig. 2). 


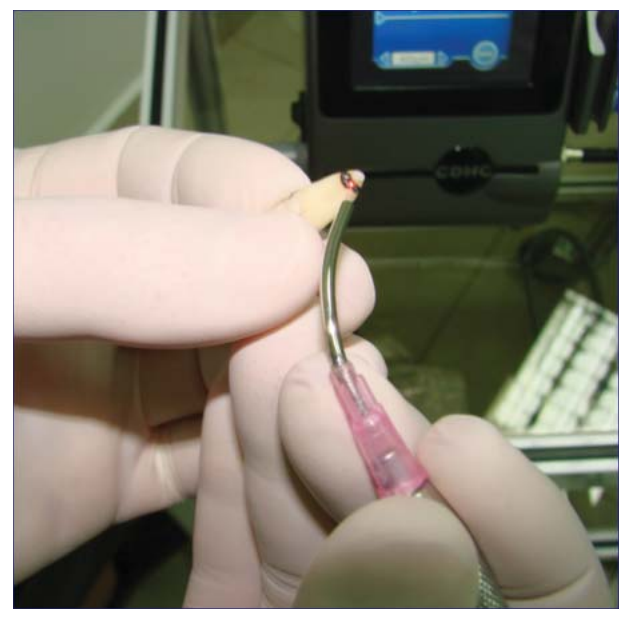

Fig. 2. Laser apex resection

Successful resection of the tooth apex has been performed at: $3 \mathrm{~W} ; 4 \mathrm{~W} ; 5 \mathrm{~W}$; $6 \mathrm{~W}$ and $7 \mathrm{~W}$ power. When laser resected the tooth apex carbonizes (Fig. 3).

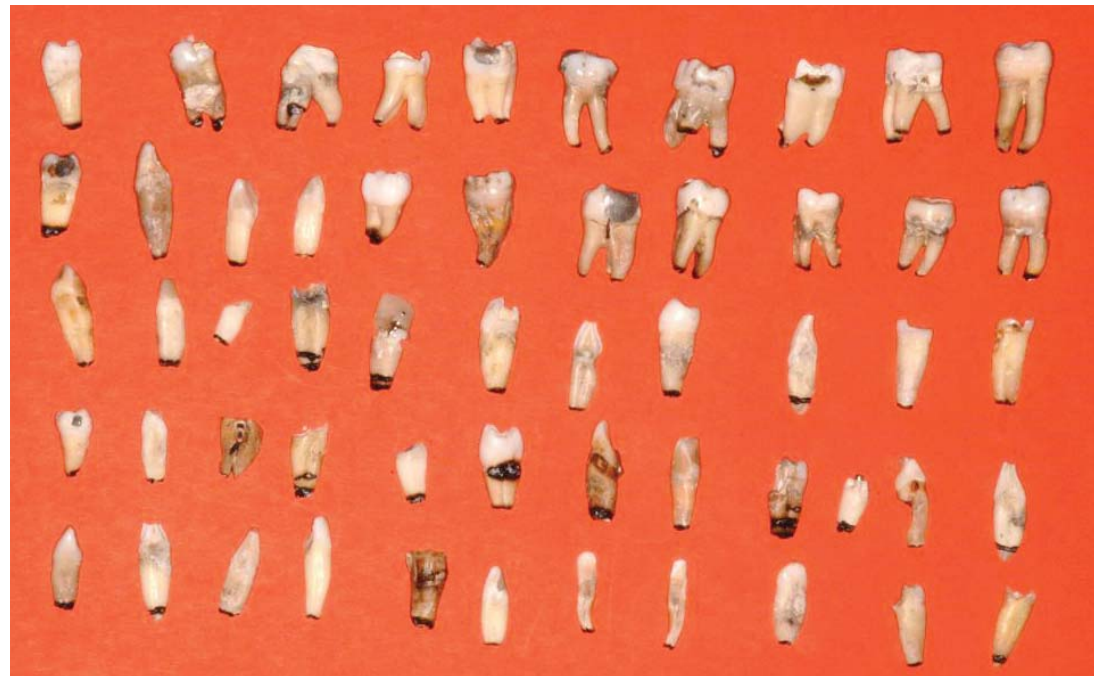

Fig. 3. Carbonized apexes of the laser treated teeth

To achieve the result at low emission power ( $3 \mathrm{~W}$ and $4 \mathrm{~W}$ ) more time is necessary - an average of $56 \mathrm{~s}$., while at larger power the time will be shortened to an average of $20 \mathrm{~s}$. It should be held in mind that the experimental design was carried out in dry conditions, in which the absorption of the laser light from the tissue is maximal. The carbonized dental tissue can be easily removed by curette (Fig. 4). 


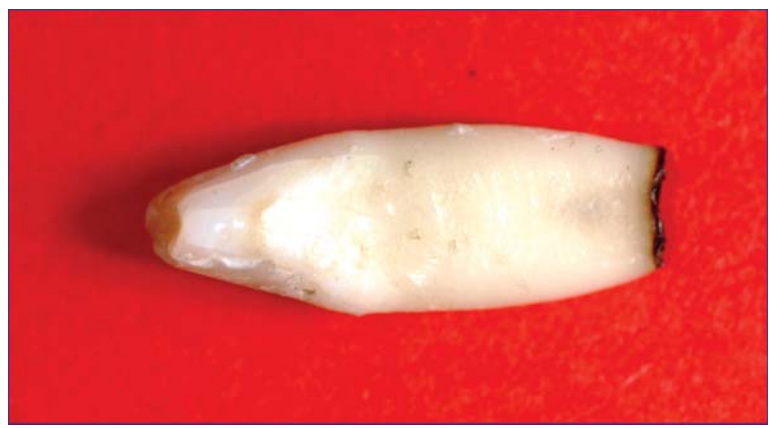

Fig. 4. Tooth with laser apical resection

\section{CONCLUSION}

The conducted experimental studies give reason to further investigations in this direction which can be the basis of clinical approbation of "Denlase" laser method for apical osteotomy.

\section{REFERENCES}

1. Zerbinati, L. P. et al. Assessment of marginal adaptation after apicoectomy and apical sealing with Nd:YAG laser. - Photomed. Laser Surg., 30, 2012, № 8, 444-450.

2. Garip, H., Y. Garip, H. Oruçoğlu et S. Hatipoğlu. Effect of the angle of apical resection on apical leakage, measured with a computerized fluid filtration device. - Oral Surg. Oral Med. Oral Pathol. Oral Radiol. Endod., 111, 2011, № 3, 50-55.

3. de Moura,A. A. et al. Morphological assessment of dentine and cementum following apicectomy with Zekrya burs and Er: YAG laser associated with direct and indirect Nd:YAG laser irradiation. Oral Surg. Oral Med. Oral Pathol. Oral Radiol. Endod., 109, 2010, № 4, e77-82.

4. Calişka n, M. K., N. K. Parlar, H. Oruçoğlu et B. Aydin. Apical microleakage of root-end cavities prepared by Er, Cr: YSGG laser. - Lasers Med. Sci., 25, 2010, № 1, 145-150.

5. D u a r t e, M. A. et al. Evaluation of apical surface roughness after root resection: a scanning electron microscopic study. - Oral Surg. Oral Med. Oral Pathol. Oral Radiol. Endod., 104, 2007, № 6, e74-76.

6. Aris u, H. D., B. Sadik, O. Bala et E.Türköz. Computer-assisted evaluation of microleakage after apical resection with laser and conventional techniques. - Lasers Med. Sci., 23, 2008, № 4, 415-420.

7. Stab holz, A. et al. Scanning electron microscopic study of the apical dentine surfaces lased with ND:YAG laser following apicectomy and retrofill. - Int. Endod. J., 25, 1992, № 6, 288-291.

8. P o z za, D. H. et al. CO(2), Er: YAG and Nd:YAG lasers in endodontic surgery. - J. Appl. Oral Sci., 17, 2009, № 6, 596-599.

9. Oliveira, R. G. et al. Scanning electron microscopy (SEM) and optical microscopy: effects of Er:YAG and Nd:YAG lasers on apical seals after apicoectomy and retrofill. - Photomed. Laser Surg., 22, 2004, № 6, 533-536.

10. P a g h d i w a I a, A. F. Root resection of endodontically treated teeth by erbium: YAG laser radiation. - J. Endod., 19, 1993, № 2, 91-94.

11. Moritz, A. et al. The carbon dioxide laser as an aid in apicoectomy: an in vitro study. - J. Clin. Laser Med. Surg., 15, 1997, № 4, 185-188.

12. C a margo, S. E. et al. Effects of Nd:YAG laser irradiation on root canal dentin wall: a scanning electron microscopic study. - Photomed. Laser Surg., 23, 2005, № 4, 399-404. 
13. Wa I I a ce, J. A. Effect of Waterlase laser retrograde root-end cavity preparation on the integrity of root apices of extracted teeth as demonstrated by light microscopy. - Aust. Endod. J., 32, 2006, № 1, 35-39.

14. E s e n, E. et al. Apical microleakage of root-end cavities prepared by $\mathrm{CO} 2$ laser. - J. Endod., 30, 2004, № 9, 662-664.

15. Francischone, C. E. et al. Apicectomy with the Er:YAG laser or bur, followed by retrograde root filling with zinc oxide/eugenol or sealer 26. - Photomed. Laser Surg., 23, 2005, № 4, 395-398.

16. Maillet, W. A., C. D. Torneck et S. Friedman. Connective tissue response to root surfaces resected with Nd:YAG laser or burs. - Oral Surg. Oral Med. Oral Pathol. Oral Radiol. Endod., 82, 1996, № 6, 681-690.

17. González, M., J. A. Banderas, V. Rodríguez et V. M. Castaño. Particle-induced X-ray emission and scanning electron microscopic analyses of the effects of $\mathrm{CO} 2$ laser irradiation on dentinal structure. - J. Dent., 27, 1999, № 8, 595-600.

18. The od oro, L. H. et al. Effect of Er:YAG and Diode lasers on the adhesion of blood components and on the morphology of irradiated root surfaces. - J. Periodontal Res., 41, 2006, № 5, 381-390.

19. $\mathrm{He}, \mathrm{H}$. et al. Thermal and morphological effects of the pulsed Nd:YAG laser on root canal surfaces. - Photomed. Laser Surg., 27, 2009, № 2, 235-240. doi: 10.1089/pho.2008.2244.

20. A ra k i, A.T., Y. Ibraki, T. Kawakami et J. L. Lage-Marques. Er:Yag laser irradiation of the microbiological apical biofilm. - Braz. Dent. J., 17, 2006, № 4, 296-299.

21. A ren s, D. L., G. C. Levy et I. M. Rizoiu. A comparison of dentin permeability after bur and laser apicoectomies. - Compendium, 14, 1993, № 10, 1290, 1292, 1294 passim; quiz 1298.

22. Nis him o to, Y. et al. Effect of pulse duration of Er: YAG laser on dentin ablation. - Dent. Mater J., 27, 2008, № 3, 433-439.

23. B odrum I u, E. et al. Temperature variation during apicectomy with Er:YAG laser. - Photomed. Laser Surg., 30, 2012, № 8, 425-428. doi: 10.1089/pho.2012.3256. Epub 2012 Jun 25.

24. Reyhanian, A., S. Parker et J. Moshonov. The use of the erbium yttrium aluminium garnet $(2,940 \mathrm{~nm})$ in a laser-assisted apicectomy procedure. - Br. Dent. J., 205, 2008, № 6, 319-323. doi: 10.1038/sj.bdj.2008.804.

25. Lustosa-Pereira, A. C. et al. Analysis of the morphology and composition of tooth apices apicectomized using three different ablation techniques. - Med. Oral Patol. Oral Cir. Bucal., 16, 2011, № 2, e225-320.

26. B e e n a, V. S. Laser application in dentistry. - J. Dent.,. 1992, Indian Dent. Assoc., 63, 1992, № 3, 1-7.

27. Kienle, A. et al. The bleaching of teeth: a review of the literature. - J. Dent., 34, 2006, 412-419.

28. Ribe iro, A. et al. Effects of diode laser $(810 \mathrm{~nm})$ irradiation on root canal walls: Thermographic and morphological studies. - J. Endod., 33, 2007, № 3, 252-255.

29. Wals h, L. J. The current status of laser application in dentistry. - Australian Dent. J., 48, 2003, № 3, 146-155.

30. Frie d, D., R. E. Featherstone et J. D. B., W. Seka. Nature of light scattering in dental enamel and dentin at visible and near-infrared wavelengths. - Appl. Opt., 34, 1995, 1278-1285.

31. Uzun ova, P. et al. Experimental study of the Penetration of Laser Radiation with red and yellow wavelengths and Different Polarization in Human Tooth complexes. - ILLA/LTL 2006, 280-285.

32. U z u n ova, P. et al.. Analysis of the penetration of laser radiation in dental tissue. - J. Techn. Univ. Sofia, br. Plovdiv, 16, 2011, 179-183.

\section{Corresponding author:}

Tz. Uzunov

Medical University, Sofia

Faculty of Dental Medicine

1 Sv. Georgi Sofiyski st.

Bg -1431 Sofia 